\title{
Common Metal Die Attachment for SiC Power Devices Operated in an Extended Junction Temperature Range
}

\author{
Satoshi Tanimoto ${ }^{1,2}$, a, Kohei Matsui ${ }^{1,3}$, Yusuke Zushi ${ }^{1,2}$, Shinji Sato ${ }^{1,4}$, \\ Yoshinori Murakami $^{1,2}$, Masato Takamori ${ }^{5}$ and Takashi Iseki ${ }^{5}$ \\ ${ }^{1}$ R\&D Partnership for Future Power Electronics Technology (FUPET), Japan \\ ${ }^{2}$ Nissan Motor Co., Ltd., 1, Natsushima-cho, Yokosuka 237-8523, Japan \\ ${ }^{3}$ Fuji Electric Co., Ltd., Fuji-machi, Hino, Tokyo 191-8502, Japan \\ ${ }^{4}$ Sanken Electric Co., Ltd., 3-6-3, Kitano, Niiza, Saitama 352-8666, Japan \\ ${ }^{5}$ Sumitomo Metal Mining Co., Ltd., 6-1, Suehiro-cho 1-chome, Ome, Tokyo 198-8601, Japan \\ as-tanimoto@mail.nissan.co.jp
}

Keywords: high temperature, power device, die attachment, solder, common metal, Zn-Al, package

\begin{abstract}
A new high-temperature die attachment system that is cost effective has been strongly desired for SiC power applications in electric vehicles and consumer electronics. This paper presents preliminary results for $\mathrm{SiC} / \mathrm{Zn}-\mathrm{Al} / \mathrm{Cu}-\mathrm{SiN}$ die attachments using eutectic $\mathrm{Zn}-\mathrm{Al}$ solder $\left(\mathrm{m} . \mathrm{p} .=356^{\circ} \mathrm{C}\right.$ ), focusing on preparation and die-shear reliability. Superior wettability and reproducibility were achieved in the soldering process. It was found that the attachments were viable at least for short-term application in a temperature range up to $300^{\circ} \mathrm{C}$. Reliability test results revealed that they could withstand storage for 1500 hours at $200^{\circ} \mathrm{C}$ and thermal cycle stress of 1500 cycles between $-40^{\circ} \mathrm{C}$ and $200^{\circ} \mathrm{C}$.
\end{abstract}

\section{Introduction}

$\mathrm{SiC}$ power devices can operate stably even at higher junction temperatures $\left(\mathrm{Tj}>200^{\circ} \mathrm{C}\right)$. This feature is extremely attractive for power applications in electric vehicles and consumer electronics where small size, light weight, and cost effectiveness are key attributes [1]. Extended $\mathrm{Tj}$ operation naturally needs a die attachment system capable of withstanding higher temperatures and greater $\Delta \mathrm{Tj}$ cycle stress. To date, die attachment systems using precious metal solder such as eutectic Au-Si (m.p. = $\left.363^{\circ} \mathrm{C}\right)[2]$ and $\mathrm{Au}-\mathrm{Ge}\left(\mathrm{m} . \mathrm{p} .=356^{\circ} \mathrm{C}\right)$ [3] have been promising in terms of reliability and availability [2] but not cost. Hence, the development of a new attachment system using a common metal solder has been strongly desired. This paper describes the preliminary results obtained for a eutectic $\mathrm{Zn}-\mathrm{Al}$ attachment system in which $\mathrm{SiC}$ dies were soldered with $\mathrm{Cu}$ foil on a $\mathrm{SiN}$ ceramic substrate. Die shear strength reliability data are reported here for the first time.

\section{Experimental}

Eutectic Zn-5 mass\% Al (m.p. $=382^{\circ} \mathrm{C}$ ) sheets purchased from Sumitomo Metal Mining Co., Ltd. were used as the die attach material in this work. They contained a small amount of Ge and $\mathrm{P}$ and measured either $100 \mu \mathrm{m}$ or $30 \mu \mathrm{m}$ in thickness. The test dies $\left(2 \times 2 \mathrm{~mm}^{2}\right.$ in area and $0.3 \mathrm{~mm}$ in thickness), having Ni-based contacts and $\mathrm{Ti} / \mathrm{Ni} / \mathrm{Ag}$ metallization at the backside, were fabricated in-house from $\mathrm{n}+4 \mathrm{H}-\mathrm{SiC}$ wafers as detailed in ref. 3. A SiN ceramic with $\mathrm{Cu}$ foil electroless-plated with $5-\mu \mathrm{m}$ thick Ni $\left(20 \times 18 \mathrm{~mm}^{2}\right.$ in area and $0.32 \mathrm{~mm}$ in thickness, Hitachi Metals Ltd.) was selected as the substrate with a $0.3-\mathrm{mm}$-thick $\mathrm{Cu}$ foil. The Ni surface was finished by DC sputtering of 150-nm-thick $\mathrm{Cu}$. Figure 1 shows a schematic of the cross-sectional structure of the test samples. Die attachment was performed with an SRO-704 vacuum reflow soldering system (ATV Technology $\mathrm{GmbH}$ ), in which a small, square $\mathrm{Zn}-\mathrm{Al}$ chip was inserted between an $\mathrm{SiC}$ die and the $\mathrm{Cu}$ foil. Typical reflow duration and maximum temperature were 1 minute and $415^{\circ} \mathrm{C}$, respectively. Eight dies were 
simultaneously soldered on one SiN substrate (Fig. 2). A standard die shear test was carried out using a Dagy 4000 bond tester equipped with a substrate heating option.

For reliability assessment, storage tests and thermal cycle tests were conducted at $200^{\circ} \mathrm{C}$ using an STH-120 oven (ESPEC CORP.) and between $-40^{\circ} \mathrm{C}$ and $200^{\circ} \mathrm{C}$ using a TSE-11-AS test system (ESPEC CORP.), respectively. In these reliability tests, test samples (substrates with eight dies) were picked out one by one according to their planned schedules, and seven dies per sample were subjected to shear tests to evaluate the die shear strength at room temperature. The detailed testing procedures are described in ref. 3 .

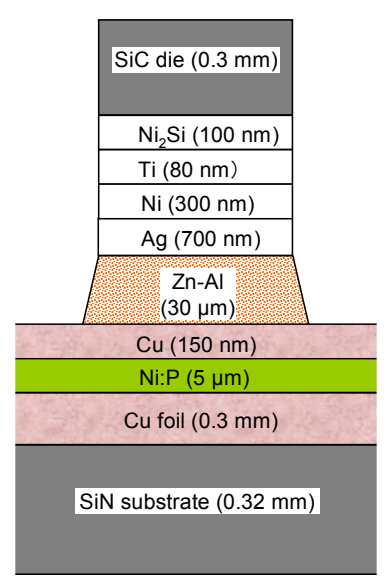

Fig. 1 Typical cross-sectional structure of a test sample assuming that no metal intermixing occurs.

\section{Results and Discussion}

The major problems previously encountered in $\mathrm{Zn}-\mathrm{Al}$ soldering were less wettability to the substrate [4] and self-fracturing of the solder layer after soldering. For the former problem, Yamada and his coworkers indicated that the use of a $\mathrm{Zn}$-Al solder sheet the surface of which was covered with thin film $\mathrm{Cu}$ could significantly improve wettability [5]. However, we could not duplicate their results with our experimental setup in spite of forming and using similar sheets. After repeated trials based on metallurgical considerations and close observation, the essential conditions were found for the formation of a strong and reproducible attachment: (1) $\mathrm{Cu}$ finish on the plated $\mathrm{Ni}$, (2) use of a solder chip smaller in size than the $\mathrm{SiC}$ die, (3) reflow under a reduced pressure $(<100 \mathrm{~Pa})$ and (4) application of a suitable load $\left(>5 \mathrm{~g} / \mathrm{mm}^{2}\right)$ to the $\mathrm{SiC}$ die during reflow. Figure 2 shows a typical $\mathrm{Zn}$-Al die attachment sample fabricated under these conditions. Solder spillage extended as much as 3 $\mathrm{mm}$ from the edge of the $\mathrm{SiC}$ die, clearly indicating superior wettability of the solder. Figure 3 is an SEM photograph showing a cross-section of the die attach sample in Fig. 2. We can see from this micrograph that the $\mathrm{Zn}-\mathrm{Al}$ solder rigidly joined the $\mathrm{SiC}$ die to the $\mathrm{Cu}$ foil without any cracking and that an off-eutectoid structure containing big hcp-Zn grains formed in the solder layer, as expected from the Zn-Al binary phase diagram [6].

The shear strength of the SiC dies was measured at various elevated temperatures. Seven dies were examined at each temperature level. Figure 4 shows the average shear strength as a function of the test temperature. Although the shear strength decreased with increasing temperature, it was $42.5 \mathrm{MPa}$

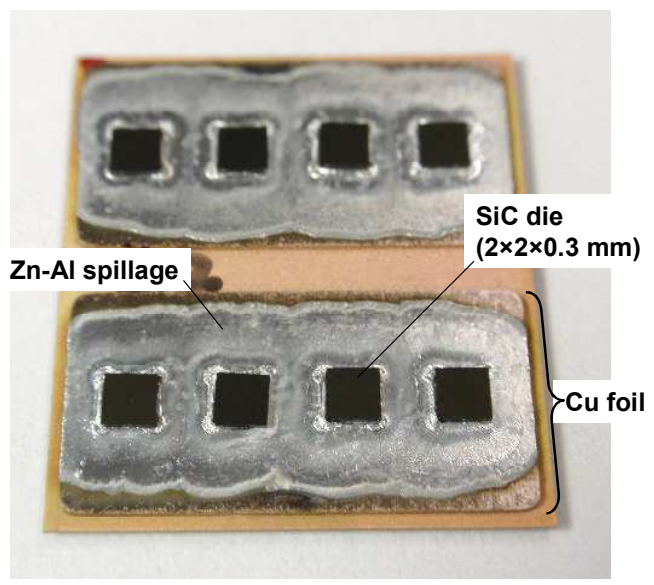

Fig. 2 A typical $\mathrm{Zn}-\mathrm{Al}$ die attachment system on a $\mathrm{Cu}$-finished $\mathrm{SiN}$ substrate.

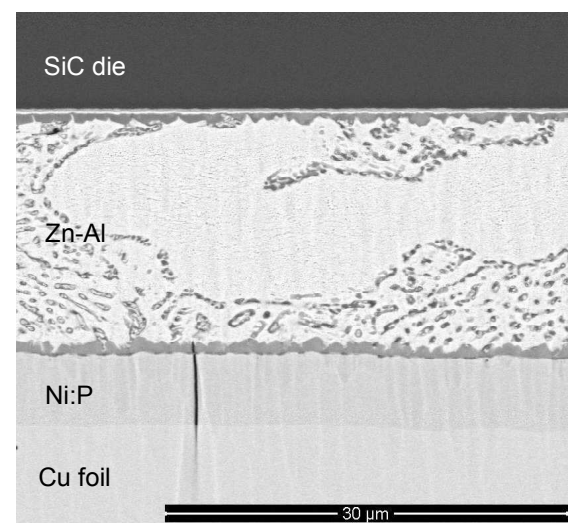

Fig. 3 A scanning electron micrgram (SEM) showing a cross-section of a $\mathrm{Zn}-\mathrm{Al}$ die attach system. 


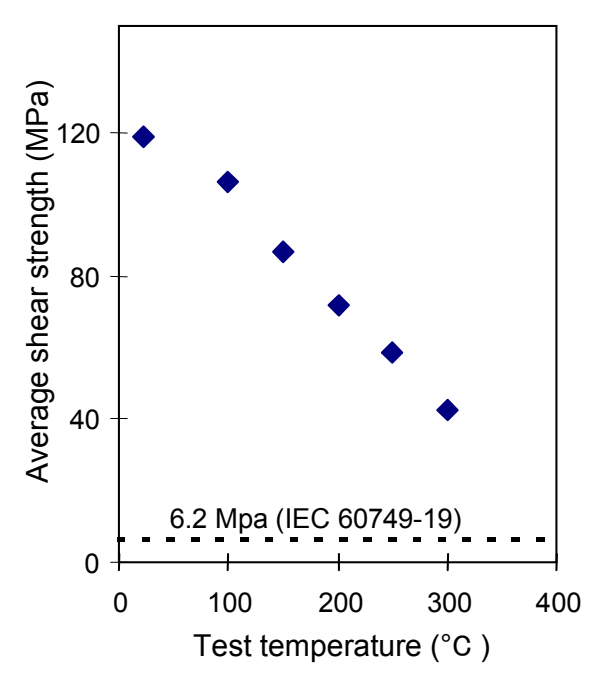

Fig. 4 The average shear strength as a function of the shear test temperature.

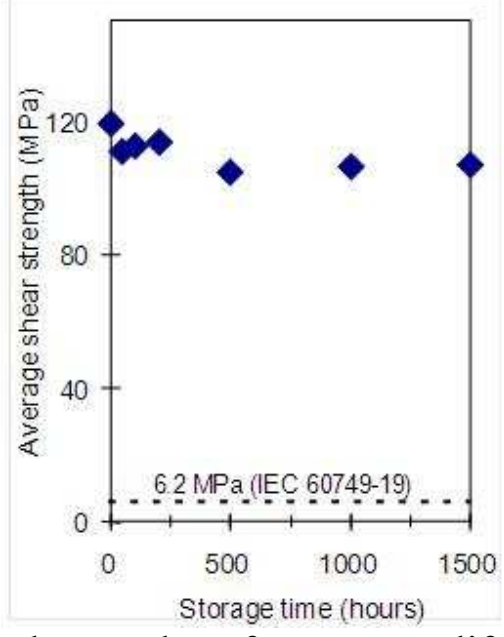

Fig. 5 The results of a storage life test at $200^{\circ} \mathrm{C}$ where the average shear strength is plotted as a function of the storage time.

even at $300^{\circ} \mathrm{C}$, which is seven times higher than the IEC standard of $6.2 \mathrm{MPa}$ specified in Document 60749-19 [7] and is comparable to that of the Au-Ge die attachment at the same temperature [3]. The shear plane of a typical sample tested at RT, $100^{\circ} \mathrm{C}, 200^{\circ} \mathrm{C}$ and $300^{\circ} \mathrm{C}$ was investigated by SEM-EDS (scanning electron microscopy-energy dispersive x-ray spectroscopy). The EDS analysis of the substrate shear face revealed that regardless of the shear test temperature, shear fracture occurred mainly in the solder layer and sometimes at the interface between the solder and the plated-Ni on the $\mathrm{Cu}$ foil.

Figure 5 shows the results of a $200^{\circ} \mathrm{C}$ storage test, where the average shear strength is plotted as a function of the storage time. The shear strength of our $\mathrm{SiC} / \mathrm{Zn}-\mathrm{Al} / \mathrm{Cu}-\mathrm{SiN}$ attachment declined slightly in the early stage and then stayed constant within an acceptable range of experimental error. The shear strength after 1500 hours still remained at $106 \mathrm{MPa}$, a value that is more than one order of magnitude higher than the IEC standard [7].

Figure 6 shows the results of the thermal cycle tests, with the change in the average shear strength plotted as a function of the number of cycles. Although the shear strength gradually declined with an increasing number of cycles, our attachment maintained a sufficient and acceptable strength level of $78 \mathrm{MPa}$ even after 1500 cycles. In order to investigate the cause of the shear strength decline, the

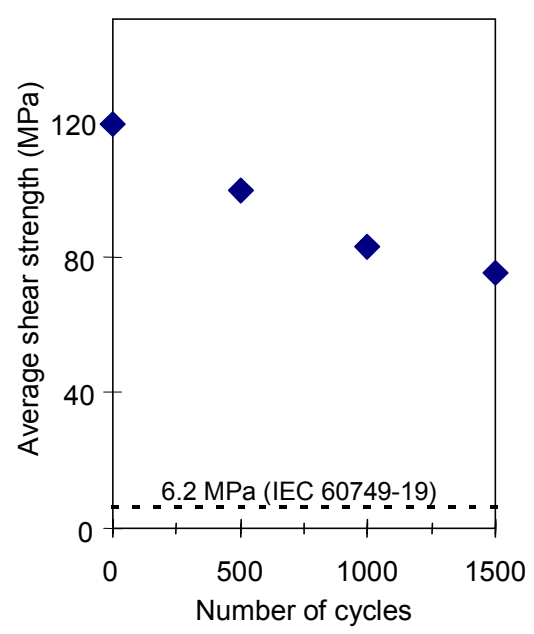

Fig. 6 The results of a thermal cycle test between $-40^{\circ} \mathrm{C}$ and $200^{\circ} \mathrm{C}$ where the average shear strength is plotted as a function of the number of cycles.

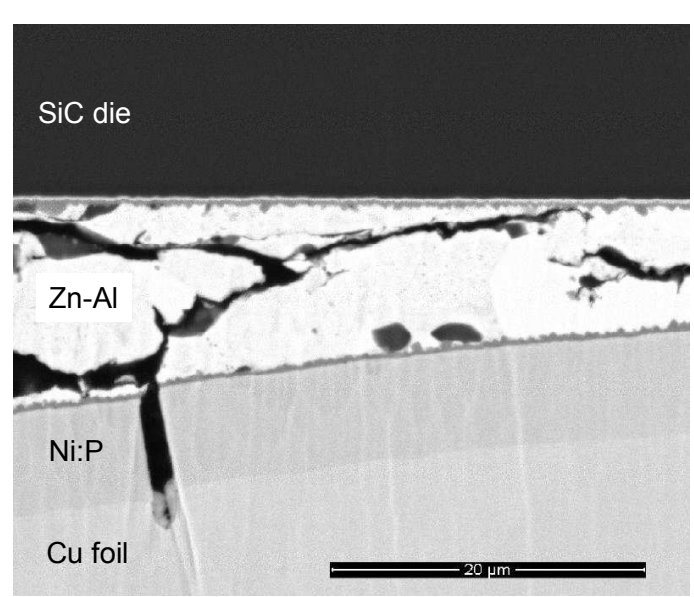

Fig. 7 A scanning electron micrograph (SEM) showing a cross-section of a die attach system after 1500 cycles in a thermal cycle test between $-40^{\circ} \mathrm{C}$ and $200^{\circ} \mathrm{C}$. 
sample tested for 1500 cycles was analyzed using SEM-EDS. This shear face analysis by EDS revealed that the main fracture plane was in the solder layer, identical to that of the as-attached sample described earlier. Figure 7 is a cross-sectional SEM photograph of a selected place of the die attachment. A considerable number of cracks and their length can be seen in the $\mathrm{Zn}-\mathrm{Al}$ solder layer. These results indicated that the occurrence and progress of such cracks caused the fracture toughness of the solder layer to decline, resulting in a gradual deterioration of shear strength.

\section{Summary}

New $\mathrm{SiC} / \mathrm{Zn}-\mathrm{Al} / \mathrm{Cu}-\mathrm{SiN}$ die attachments using eutectic $\mathrm{Zn}-5$ mass $\% \mathrm{Al}$ solder $\left(\mathrm{m} . \mathrm{p} .=356^{\circ} \mathrm{C}\right)$ were described in terms of their preparation and die-shear reliability. The essential soldering conditions were presented for the formation of a strong and reproducible attachment. It was found that the attachments can be utilized without any problem in short-term applications in a temperature range up to $300^{\circ} \mathrm{C}$. Storage tests at $200^{\circ} \mathrm{C}$ revealed that, after an initial slight decline, the die shear strength stayed constant at a sufficient level $(\sim 106 \mathrm{MPa})$ for at least 1500 hours. Thermal cycle test results clearly indicated that the attachments can withstand thermal cycle stress for more than 1500 cycles between $-40^{\circ} \mathrm{C}$ and $200^{\circ} \mathrm{C}$. The storage and thermal cycle tests are still in progress at this point and will continue for 3000 hours and 3000 cycles. New results and findings will be reported elsewhere in the near future.

\section{Acknowledgments}

This work was supported by the Green IT project directed by the New Energy and Industrial Technology Development Organization (NEDO) of Japan. The authors wish to thank Dr. Sumio Ashida (NEDO), Dr. Tomoyuki Yamada and Dr. Toshimi Wada (FUPET), Dr. Haruhito Mori and Masaki Nakano (Nissan Motor), and Dr. Hajime Shimizu and Dr. Hajime Okumura (AIST, Japan) for their encouragement, and Ms. Ai Kawashima and Ms. Yoshiko Sato (FUPET) and Mr. Wataru Itou and Ms. Yoshie Horise for their technical support.

\section{References}

[1] J. Hornberger, A. B. Lostetter, K. J. Olejniczak, T. McNutt, S. Magan Lal and A. Mantooth: 2004 IEEE Aerospace Conference Proceedings (Big Sky, MT, USA, 2004), pp. 2583-2554.

[2] P. Zheng, A. Wiggins, R. W. Hohnson, R. V. Frampton, S. J. Adam and L. Peltz: Proceedings, IMAPS International Conference and Exhibition on High Temperature Electronics 2008 (Albuquerque, NM, USA, 2008), pp. 213-219.

[3] S. Tanimoto, K. Matsui, Y. Murakami, H. Yamaguchi and H. Okumura: Proceedings, IMAPS International Conference and Exhibition on High Temperature Electronics 2010 (Albuquerque, NM, USA, 2010), pp. 32-39.

[4] T. Shimizu, H. Ishikawa, I. Ohnuma and K. Ishida: J. Electron. Mater., Vol. 28, p. 1172 (1999).

[5] Y. Yamada, Y. Takaku, Y. Yagi, I. Nakagawa, T. Atsumi, M. Shirai, I. Ohnuma and K. Ishida: ICEP 2009 Proceedings (Kyoto, Japan, 2009), pp. 696-699.

[6] http://www.crct.polymtl.ca/FACT/phase_diagram.php?file=Al-Zn.jpg\&dir=BINARY

[7] International Standard IEC 60749-19. 